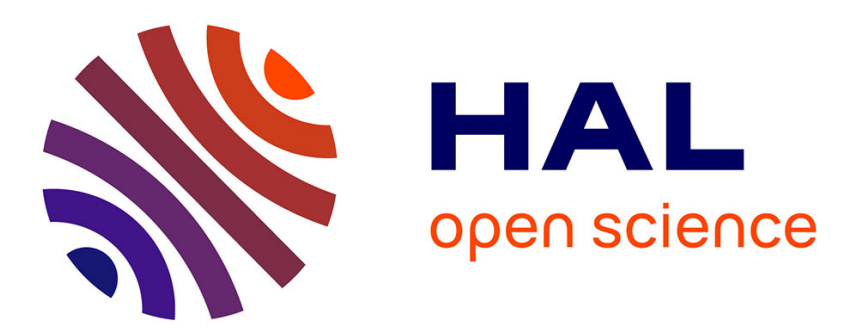

\title{
A Production System Reconfiguration Model Based on Repair Approach
}

\author{
Feno Mahenina Remiel, Aline Cauvin, Alain Ferrarini
}

\section{To cite this version:}

Feno Mahenina Remiel, Aline Cauvin, Alain Ferrarini. A Production System Reconfiguration Model Based on Repair Approach. IFIP International Conference on Advances in Production Management Systems (APMS), Sep 2014, Ajaccio, France. pp.344-351, 10.1007/978-3-662-44733-8_43 . hal01387269

\section{HAL Id: hal-01387269 \\ https://inria.hal.science/hal-01387269}

Submitted on 25 Oct 2016

HAL is a multi-disciplinary open access archive for the deposit and dissemination of scientific research documents, whether they are published or not. The documents may come from teaching and research institutions in France or abroad, or from public or private research centers.
L'archive ouverte pluridisciplinaire HAL, est destinée au dépôt et à la diffusion de documents scientifiques de niveau recherche, publiés ou non, émanant des établissements d'enseignement et de recherche français ou étrangers, des laboratoires publics ou privés.

\section{(c)(1)}

Distributed under a Creative Commons Attribution| 4.0 International License 


\title{
A production system reconfiguration model based on repair approach
}

\author{
FENO Mahenina Remiel*, Aline CAUVIN*, Alain FERRARINI* \\ * Aix-Marseille University - ENSAM - LSIS UMR CNRS 7296 \\ Avenue Escadrille Normandie Niemen, 13397 Marseille, France \\ e-mail: \{remiel.feno, aline.cauvin, alain.ferrarini\}@1sis.org
}

\begin{abstract}
The frequency of new product introduction requires adaptable production system. In this context, this paper deals with the reconfiguration issue during factory layout design regarding the introduction of a new product in an existing production line. A repair approach from planning recovery is explored to address this issue. We show that long term performance can be reached if future products can be integrated easily in the existing production system with low disruptions on current operations during the reconfiguration phase.
\end{abstract}

Keywords: Factory design, reconfiguration, assembly systems, repair planning

\section{Introduction}

Due to rapid changing market, product lifecycle is decreasing and model mix is high in most industrial organization. This generates highly individualized engineering tasks and repetitions of development and validation activities. In this paper we propose an approach which allows analyzing production line reconfiguration process taking into account the future product to be produced.

Even though a lot of research work has been done on flexible and reconfigurable production systems, the reconfiguration process itself is less supported by suitable methodology. The different cases of the reconfiguration problem and the activities involved in the reconfiguration process need first to be categorized. The operations to be performed are intended to minimize the disruption on the existing assembly line. Adequate selection criteria need to be identified to assess each alternative.

A critical review of various approaches in design and reconfiguration of assembly systems reported in the recently published literature is first presented with a special emphasis on new product introduction. A methodology based on repair is introduced to address the reconfiguration issue. Finally, a case study is presented to illustrate the introduction of new products on existing assembly line. 


\section{Context and motivation}

The context of this study is about capacity requirement analysis and product allocation to assembly unit during the preliminary factory design. Configuration is the arrangement of the production system layout and the associated assembly process to achieve production objectives. Reconfiguration is a more difficult process than initial configuration because we need to consider not only the desired outcome of a configuration process but also find the most suitable way to reach this state.

Reconfigurability is the ability to add, remove and/or rearrange in a timely and costeffective manner the components and functions of a system which can result in a required set of alternate configurations [1]. Several cases may arise when introducing new product (1) develop new assembly line, (2) expand existing one or (3) reconfigure existing facility. We consider the reconfiguration process as any change between production phases. There is a need for a new approach to analyze these reconfiguration processes by taking into account future change and the complexity of the system.

\subsection{The reconfiguration problem}

The reconfiguration problem is similar to the initial design process, except that there are existing facility layout and resources constraints. Each new product introduction brings the following issues: when and how do we reconfigure? The first one depends on the performance required for the next period; if it is not satisfactory then the reconfiguration is considered. We will focus on the second one which is related to the choice of adequate reconfiguration operations to perform in order to satisfy the new product change and existing constraints.

Several alternatives can be identified and they usually differ by their flexibility level. The decision to develop flexible assembly line on the first product is one of the main issue in factory design. It should not be supported by profitability analysis only but by technical performance criteria as well. This is because economic advantages of flexible systems appear on long period and the decision does not refer to the same product. On the other hand the profitability rule for a facility investment in most companies is less than one year, which does not give advantage to flexible solutions.

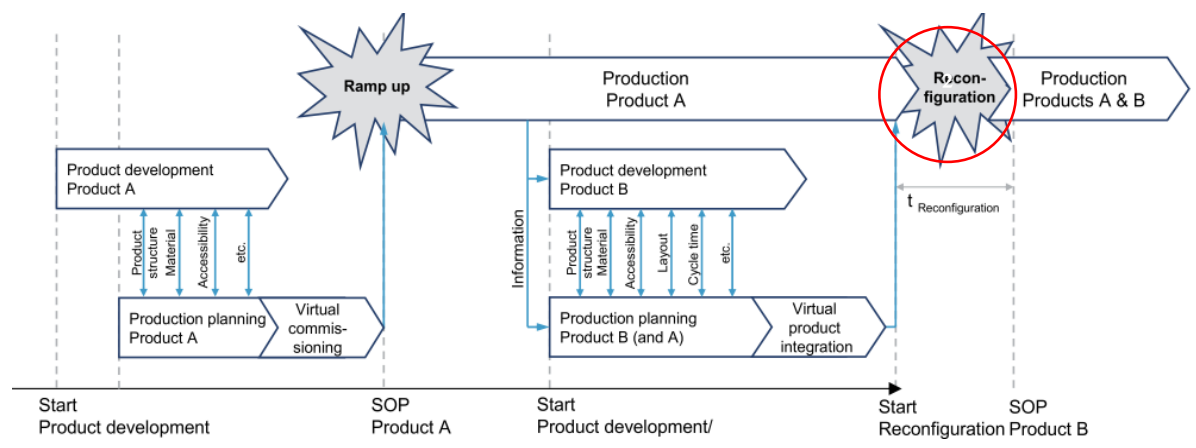

Fig. 1. Reconfiguration issue and the production system lifecycle [2] 
Typical issue when introducing a new product $\mathrm{B}$ in a production system already producing A is represented in Fig.1. The decision we try to formalize is related to the operations to perform during the reconfiguration phase. Some research works related to this problem and their contributions are described below.

\subsection{Literature review}

Several researches addressed the reconfiguration problem in different contexts. Most of them focus on operational planning and control of reconfigurable production system (RPS). Some deal with the balancing problem in reconfigurable manufacturing system (RMS) with genetic algorithm [3]. Economic justification of changeability in reconfigurable assembly systems (RAS) is proposed with a strategic point of view. Changeability classification and enablers for reconfiguration planning are presented but no specific methodology for the reconfiguration process has raised [4].

Others developed a methodology to choose between dedicated, reconfigurable and flexible production system based on cost analysis and capacity investment [5]. Reconfigurability measurement has been also proposed based on axiomatic design and structure design matrix [6].

Some research works contributed to reconfiguration planning to minimize total lifecycle cost on several product generations. Assembly system reconfiguration planning problem (ASRP) has been resolved by dynamic programing and genetic algorithm [7]. Instead of generating new assembly plans from scratch, reconfigurable process planning (RPP) intends to generate portion of the master assembly planning referring to the new operations which are optimally positioned within the master plan [8] [9]. This approach enables local reconfiguration of assembly sequence plans.

A premise of reconfiguration methodology is proposed by [12], where several structures of RMS have been assessed according to their productivity. The study involves a simplified production line with only five stations to enable exact method analysis.

All the previous approaches deal with either operational planning and control of reconfigurable production system or the reconfiguration planning problem. Few deals with the operations to perform for the reconfiguration. The impact of the solution on the initial system configuration is not really taken into account. In these circumstances, adequate methodology is then required to address these issues to minimize the impact of the reconfiguration while taking into account the problem complexity.

In the following, we will focus on a planning repair methodology that has been used to minimize the disruption on the existing organization. It has been applied to supply chain, building project and workshop rescheduling [10] [11]. The relevant results of this approach require particular attention since our objective is to minimize the impact of new product introduction on the initial factory layout configuration. We propose to analyze their projections on the reconfiguration of assembly system domain. 


\section{Reconfiguration approach}

The reconfiguration problem can be seen as a planning repair as long as the objective is to minimize disruption on existing production system. The aim in project planning repair is to minimize the impact of the disruption on the initial master plan and associated organizational aspects, while in production system reconfiguration the aim consists in minimizing the impact of new product introduction on the initial system configuration. A plan repair can be seen as planning with re-use of fragments of the previous plan [13]. It can be defined as a local and limited modification of a previously calculated planning. The approach is particularly suited to solve scheduling problem or partially deficient resulting from any kind of disruption.

The principle of the studied method comes from the cooperative and distributed problem solving that has been already implemented in production and logistics, and extended to building site organization [14]. This principle is based on the development of solutions by the actors themselves for limiting the impact of disruptions throughout the organization while ensuring the achievement of objectives. Rather than implementing a new planning calculation, the purpose is to repair the existing plan.

In order to achieve this goal, strategies for responding to disruptions have been defined consisting in a sequence of repair operations applied to the disrupted planning. Initially these operations consisted in time shifts or tasks permutations within one or more resources. Solving strategies implement sequences of repair operations in order to limit the impact of disruptions on the organization. Each implemented strategy will be evaluated in term of cost and delay in order to decide of using a strategy.

The same idea is retrieved in a factory design and reconfiguration with an additional dimension to the timeline of a plan. Repair operations consist in limiting tasks that minimize the impact of the new product on the current production system configuration. Operations may involve layout change, additional resources, equipment replacement or logistic concept adaptation [2]. The reconfiguration approach is based on repair method to find reconfiguration solutions initiated by the decision to introduce a new product. Designers may therefore focus on minimizing the impacts of the new system configuration on production cost and logistics, layout requirement, operation and workforce need or equipment availability. To do so, an analogy between both domains is presented, followed by first steps of the decision process.

\subsection{Analogy between system reconfiguration and planning repair}

Here we use the principle of analogy to transpose some concepts of the planning problem to the reconfiguration issue. This analogy enables us to consider assembly reconfiguration issue as a planning repair, which takes us from a temporal point of view to space occupation point of view. The idea is to show common concepts and methodology to use existing resolution based on repair approach.

In planning problem, a task is composed of several operations which need to be assigned to an actor with limited time capacity. Each operation may require one or sev- 
eral resources to perform the task. In the reconfiguration problem, an assembly unit is composed of several workstations to allocate on a limited layout. The same analogy between time and space has been successfully used for the arrangement of cable harness design [16] where scheduling method have been used to arrange cable allocation.

\begin{tabular}{|l|l|}
\hline \multicolumn{1}{|c|}{ Task } & \multicolumn{1}{c|}{ Assembly unit } \\
\hline Temporal attributes & Spatial attributes \\
\hline- Duration (required time) & - Surface (required space) \\
\hline- Start date & - Loading station \\
\hline- End date & - Unloading station \\
\hline- Temporal margin & - Available space on the layout \\
\hline Physical attribute & Physical attribute \\
\hline Working unit produced by the task & - Production capacity in jop per hour \\
\hline Resources & Ressources \\
\hline- Equipment & - Workstation \\
\hline- Tools & - Tooling and fixtures \\
\hline Actors & Worker \\
\hline- Quantity & - Workforce \\
\hline Structural attributs & Structural attributs \\
\hline- Interruptible & - Décomposable (Split into 2 blocs) \\
\hline
\end{tabular}

Table 1. Analogy between reconfiguration and planning

In our case, reconfiguration operations may involve layout change, additional resources, equipment replacement or logistic concept adaptation.

- Minor reconfiguration: develop new process with low disruption.

- Significant reconfiguration: reuse part of existing process (carry over)

- Major reconfiguration: redesign the whole factory layout.

\subsection{The decision process in production system reconfiguration}

The analogy enabled us to validate the principle of repair in a layout reconfiguration context, the next step consists in identifying and evaluates several categories of operations to perform and analyze their impact on the production system. The decision process follows the 4 steps, analysis, design, selection and implementation.

- Analyze the new product parameters and the actual assembly line capability

- Design : identify reconfiguration strategies

- Decision or selection: choose between alternatives based on several criterion

- Implementation and evaluation: implement reconfiguration operations.

\section{$4 \quad$ Reconfiguration case study}

We illustrate the design step with an automotive body shop example. For a new product introduction, an industrial company is dealing with flexibility investment decision to improve its production process. The cost of the new flexible equipment is known 
but the real operational cost is usually not. To support this decision we can compare the performance of the production system with and without the flexible equipment.

When a car body is made, the parts are first stamped from rolls of steel, the overall body is welded together to create a shell, and then the individual parts are welded together into the body on a moving assembly line. This part of the process is performed in the Body in White (BIW) workshop containing several layers:

- Mainlines or assembly units (ex: opening unit, main floor)

- Subassemblies (ex: front door) supplying the mainline.

- Cells (ex: robotic hemming cell)

- Workstation (ex: manual gun welding)

\subsection{Description of the case study}

We assume that a company produces a product $\mathrm{A}$ and plans to introduce a new product B in two years, as described in Table 2. Specific tooling for product (A) is installed on the line in Hypotheses 1 while flexible tooling is installed for products (A) and (B) in hypothesis 2 . The idea is to illustrate the reconfiguration operations at $\mathrm{T} 2$

\begin{tabular}{|l|c|c|c|}
\hline Year & $\mathbf{0}$ & $\mathbf{1}$ & $\mathbf{2}$ \\
\hline Product & $\mathrm{A}$ & $\mathrm{A}$ & $\mathrm{A}+\mathrm{B}$ \\
\hline Hyp 1 & $\mathrm{C} 0+\mathrm{a}$ & & $\mathrm{C} 1+\mathrm{b}$ \\
\hline Hyp 2 & $\mathrm{C}+\mathrm{a}$ & & $\mathrm{b}$ \\
\hline
\end{tabular}

Table 2. Investment cash flow for new product introduction
C: capacitary investment
$\mathrm{a}, \mathrm{b}$ : specific investment for product $\mathrm{A}$ or $\mathrm{B}$
C0: Tooling investment for A
$\mathrm{C} 1$ : remove tooling for $\mathrm{A}$ and install for $\mathrm{B}$

Figure 4 represents the investment cash flow for hypotheses 1 and 2 . The vertical line defines the reconfiguration phase. For the same initial capacitary investment (left side of each hypothesis), the two year cash flow cost is higher for hypothesis 1 . The study has been conducted in the context of profitability analysis between both solutions which enables us to identify investment related reconfiguration operations.

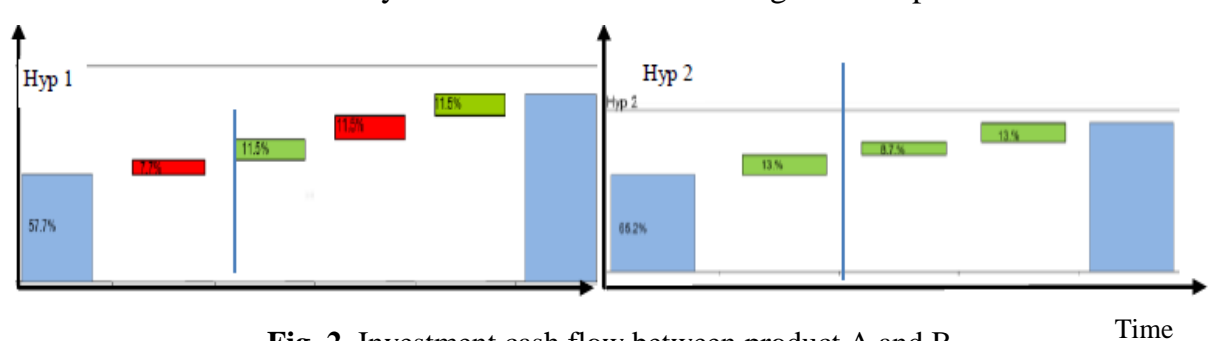

Fig. 2. Investment cash flow between product A and B

Time

The difference between the two scenarios is due to the cost of operations to perform during the reconfiguration. The main characteristics of both cases are listed below. 


\begin{tabular}{|l|l|}
\hline Hyp 1 & Hyp 2 \\
\hline Design and build additional fixtures & Build additional fixture with no extra design \\
\hline Production stop during reconfiguration & No disruption to production (week end) \\
\hline Find space for additional equipment & Space already available for added equipment \\
\hline Recalibrate and re-plan robot trajectory & No need for recalibration \\
\hline Need to restart production & No disruption to production \\
\hline
\end{tabular}

Table 3. Difference between two reconfiguration strategies

A solving strategy involves several reconfiguration operations starting from the least to the most disrupting one. Several criteria are used to assess their impact.

\subsection{Performance analysis and selection criteria}

Even though cost related performance is important in the preliminary design, technical and human factor criteria need to be considered in reconfiguration. Evaluation of the reconfiguration process is based on the final state of the system, when the previous operations have been implemented. The main selection criteria are presented for the factory level or the subassembly level (manual or an automated system).
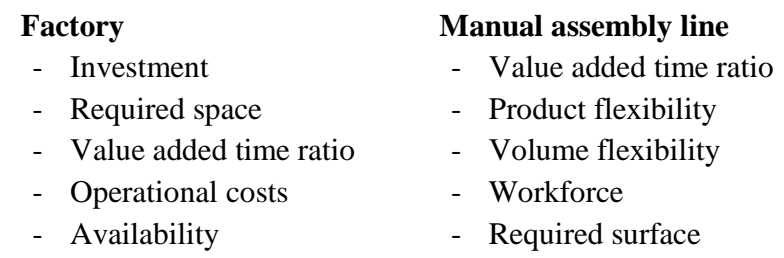

Automated assembly line

- Investment / capacity

- Product flexibility

- Volume flexibility

- Availability

- Value added time ratio

Based on these criteria, an objective function mainly based on cost and time is defined to assess the relevance of the reconfiguration strategies. Those that satisfy the new requirement and respect constraint (available space, and resource capacity) are kept.

\section{Conclusions et future research}

The aim of this paper is to propose an approach for production system reconfiguration in new product introduction. One of the conditions to reach long term performance is to ease future reconfiguration. For that, a repair approach has been explored.

The analogy between reconfiguration and planning repair showed that a task can be associated to an assembly process and other concept such as capacity or layout can be defined the same way. This approach leads us to propose a reconfiguration methodology which minimizes the impact of product change on initial system configuration.

A typology of reconfiguration operations has been presented based on the case study. In this paper, we focus on the impact of the reconfiguration operations on layout and investment. As a perspective, impact on the other criterion can be analyzed. Further analysis also needs to be done regarding the reconfiguration methodology which consists in choosing the suitable combination of these operations. Objective function based on performance criteria can be used to support this decision. 


\section{References}

[1] F. Karl, G. Reinhart, and M. F. Zaeh, "Strategic Planning of Reconfigurations on Manufacturing Resources," Procedia CIRP, vol. 3, pp. 608-613, Jan. 2012.

[2] W. Walla and J. Kiefer, "Life Cycle Engineering - Integration of New Products on Existing Production Systems in Automotive Industry,” pp. 1-6, 2011.

[3] P. a. Borisovsky, X. Delorme, and A. Dolgui, "Genetic algorithm for balancing reconfigurable machining lines," Computers \& Industrial Engineering, vol. 66, no. 3, pp. 541-547, Nov. 2013.

[4] H.-P. Wiendahl, H. a. ElMaraghy, P. Nyhuis, M. F. Zäh, H.-H. Wiendahl, N. Duffie, and M. Brieke, "Changeable Manufacturing - Classification, Design and Operation," CIRP Annals Manufacturing Technology, vol. 56, no. 2, pp. 783-809, Jan. 2007.

[5] I. Niroomand, O. Kuzgunkaya, and A. A. Bulgak, "Int . J . Production Economics Impact of reconfiguration characteristics for capacity investment strategies in manufacturing systems," Intern. Journal of Production Economics, vol. 139, no. 1, pp. 288-301, 2012.

[6] A. M. Farid, "Reconfigurability Measurement in Automated Manufacturing Systems," 2007.

[7] A. Bryan, J. Ko, S. Hu, and Y. Koren, "Co-evolution of product families and assembly systems," CIRP Annals-Manufacturing Technology, 2007.

[8] S. J. Hu, J. Ko, L. Weyand, H. a. ElMaraghy, T. K. Lien, Y. Koren, H. Bley, G. Chryssolouris, N. Nasr, and M. Shpitalni, "Assembly system design and operations for product variety," CIRP Annals Manufacturing Technology, vol. 60, no. 2, pp. 715-733, Jan. 2011.

[9] A. Azab, H. Elmaraghy, and S. N. Samy, "Reconfiguring Process Plans : A New Approach to Minimize Change," 2009.

[10] A. Cauvin, S. Fournier, and A. Ferrarini, "Disruption management in distributed organizations: a cooperative repair approach for reactive planning and scheduling," in Progress in Economic Research, vol. 23, no. 0, 2011.

[11] S. Fournier, A. Ferrarini, and A. Cauvin, "A Cooperative Agent - Based Scheduling Repair Method for Managing Disruptions in Complex Organisations," in WETICE, 20th International conference on collaboration technologies and infrastructures, 2011.

[12] Y. Koren and M. Shpitalni, "Design of reconfigurable manufacturing systems," Journal of Manufacturing Systems, vol. 29, no. 4, pp. 130-141, Oct. 2010.

[13] A. Komenda, P. Novák, and M. Pěchouček, "Domain-independent multi-agent plan repair," Journal of Network and Computer Applications, vol. 37, pp. 76-88, Jan. 2014.

[14] A. Ferrarini, S. Fournier, E. Tranvouez, C. Cauvin, and A. Cauvin, "Decision aid using multiagent models and simulation: Disruption Management in Building Site organization," in 20th International Conference on Production Research (ICPR'20), 2009, no. 2004, pp. 61 - 68.

[15] M. Zweben, E. Davis, B. Daun, and M. J. Deale, "Scheduling and rescheduling with iterative repair," Systems, Man and Cybernetics, IEEE Transactions on, vol. 23, no. 6, pp. 1588-1596, Nov. 1993.

[16] C. Cerezuela, “Contribution à l' élaboration de méthodes et d' outils d' aide à la conception dans une perspective d'ingénierie concourante. Le cas du câblage électrique," Thèse de docteur en sciences, Université d'Aix-Marseille III, 1996. 